\title{
Upstream ORF affects MYCN translation depending on exon Ib alternative splicing
} Roger Besançon*1,2, Sandrine Valsesia-Wittmann ${ }^{3}$, Clara Locher ${ }^{1}$, Céline Delloye-Bourgeois ${ }^{1}$, Lydie Furhman ${ }^{1}$, Giovani Tutrone ${ }^{1}$, Christophe Bertrand ${ }^{1}$, Anne-Catherine Jallas ${ }^{3}$, Elisabeth Garin ${ }^{3}$ and Alain Puisieux ${ }^{1,2,3}$

Address: 1'INSERM UMR590, 28 rue Laënnec, Lyon, France, ${ }^{2}$ Université de Lyon, université Lyon 1, Institut des Sciences Pharmaceutiques et Biologiques, 8 avenue Rockefeller, Lyon, 69008, France and ${ }^{3}$ Centre Léon Bérard, Laboratoire de Recherche Translationnelle, 28 rue Laënnec, Lyon, France

Email: Roger Besançon* - roger.besancon@recherche.univ-lyon1.fr; Sandrine Valsesia-Wittmann - WITTMANN@lyon.fnclcc.fr; Clara Locher - Clara.LOCHER@igr.fr; Céline Delloye-Bourgeois - delloye@lyon.fnclcc.fr; Lydie Furhman - lydiefuhrmann@hotmail.com; Giovani Tutrone - giovannitutrone@hotmail.com; Christophe Bertrand - bertrandchristophe@neuf.fr; Anne-

Catherine Jallas - jallas@lyon.fnclcc.fr; Elisabeth Garin - garin@lyon.fnclcc.fr; Alain Puisieux - puisieux@lyon.fnclcc.fr

* Corresponding author

Published: 17 December 2009

BMC Cancer 2009, 9:445 doi:10.1 I86/147|-2407-9-445
Received: 7 July 2009

Accepted: 17 December 2009

This article is available from: http://www.biomedcentral.com/I47I-2407/9/445

(C) 2009 Besançon et al; licensee BioMed Central Ltd.

This is an Open Access article distributed under the terms of the Creative Commons Attribution License (http://creativecommons.org/licenses/by/2.0), which permits unrestricted use, distribution, and reproduction in any medium, provided the original work is properly cited.

\begin{abstract}
Background: The MYCN gene is transcribed into two major mRNAs: one full-length (MYCN) and one exon Ib-spliced $\left(M Y C N^{\Delta l b}\right)$ mRNA. But nothing is known about their respective ability to translate the MYCN protein.

Methods: Plasmids were prepared to enable translation from the upstream (uORF) and major ORF of the two MYCN transcripts. Translation was studied after transfection in neuroblastoma SHEP cell line. Impact of the upstream AUG on translation was evaluated after directed mutagenesis. Functional study with the two MYCN mRNAs was conducted by a cell viability assay. Existence of a new protein encoded by the MYCN ${ }^{\Delta l b}$ uORF was explored by designing a rabbit polyclonal antibody against a specific epitope of this protein.
\end{abstract}

Results: Both are translated, but higher levels of protein were seen with MYCN ${ }^{\Delta} \mathrm{b}$ mRNA. An upstream ORF was shown to have positive cis-regulatory activity on translation from MYCN but not from MYCN ${ }^{\Delta l b}$ mRNA. In transfected SH-EP neuroblastoma cells, high MYCN dosage obtained with $M Y C N^{\Delta l b}$ mRNA translation induces an antiapoptotic effect after serum deprivation that was not observed with low MYCN expression obtained with MYCN mRNA. Here, we showed that MYCNOT: MYCN Overlap Transcript, a new protein of unknown function is translated from the upstream AUG of MYCN ${ }^{\Delta l b}$ mRNA.

Conclusions: Existence of upstream ORF in MYCN transcripts leads to a new level of MYCN regulation. The resulting MYCN dosage has a weak but significant anti-apoptotic activity after intrinsic apoptosis induction. 


\section{Background}

The MYCN gene, located in 2p23-24 [1] has been demonstrated to be composed of three exons (Fig. 1): exon 1a/b, exon 2 and exon 3, and the coding sequence for MYCN has been mapped to exons 2 and 3 [2]. Several transcripts have been described; one full length: MYCN mRNA and two alternatively spliced mRNAs; one containing exons 1a, 2 and 3: $M_{Y C N^{\Delta 1 b}}$ mRNA [2,3] and the other containing exons 1a and 3: $M Y C N^{\Delta 1 b, 2}$ mRNA [4]. Only MYCN and $M Y C N^{\Delta 1 b}$ transcripts might translate the MYCN protein. It was previously hypothesized but neither proven nor explored that an upstream AUG (uAUG) located in +1894 (according to GenBank: Y00664) of $M_{Y C N^{\Delta 1 b}}$ mRNA might translate a protein (GenBank: AAG40001.1) [5]. Moreover, as proposed by van Bokhoven et al, $M Y C N^{\Delta 1 b, 2}$ mRNA could be able to initiate translation of a new protein $(\triangle \mathrm{MYCN})$ from the same uAUG [4].

The existence of upstream open reading frames (uORFs) has been described in detail for many genes, and these uORFs could represent as much as half of the whole transcriptome [6,7]. Most studies have shown a negative cisregulatory function of the major ORF [6-8].

MYCN, a basic helix-loop-helix transcription factor that belongs to the MYC family, was initially identified as a gene amplified in neuroblastoma, the most frequent pae- diatric extra-cranial solid tumour [9]. Numerous experiments have demonstrated its importance during ontogenesis. In the developing mouse embryo, MYCN is required for normal organogenesis of the heart, neural tube, spinal ganglia, visceral arches, liver, stomach, limb buds and eyes [10]. More precisely, MYCN is essential to maintain a population of undifferentiated and proliferating progenitor cells in the brain [11] and the distal lung epithelium [12] of mouse embryos. MYCN is also able, in chick embryos, to initiate the ventral migration of cells from the neural crest to the sympathetic ganglia and to induce their differentiation into neurons [13].

The overexpression of MYCN in the presence of deregulated H-ras has been shown to contribute to the neoplastic transformation of rat embryo cells, suggesting an oncogenic role of MYCN [14]. This oncogenic role was later confirmed using MYCN-transgenic mice: targeted expression of MYCN to neural crest-derived cells under the control of the Tyrosine Hydroxylase promoter leads to the development of neuroblastoma-like tumours in all homozygous mice [15].

The amplification and overexpression of MYCN primarily found in $25 \%$ of neuroblastomas are associated with advanced tumour stage, tumour progression and poor outcome [16]. MYCN can also be overexpressed in other
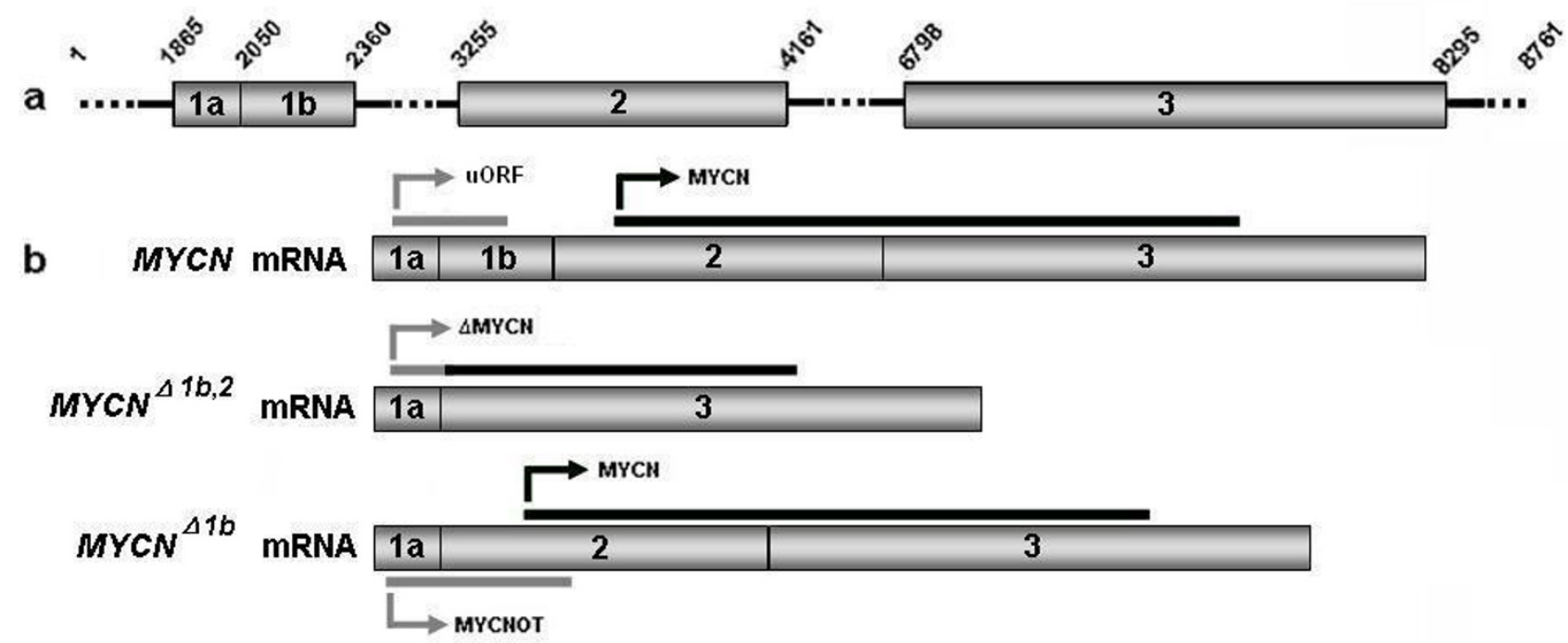

C MYCNOT:

MRGAPGNCVGAEQALARRKRAQTVAIRGHPRPPGPPGDTRAESPPDPLQSAGVLEVGA GPRLPRPPREGSTPGIKTNGAERSPQSPAGRRADAELLHVHHAGHDLQEPRPRV

\section{Figure I}

The MYCN oncogene and encoded proteins. a) Annotated sequence of MYCN according to Genbank Y00664. b) Alternative splicing and putative proteins encoded by MYCN. c) MYCNOT sequence. Bold aminoacids: shared homology with the putative $\triangle M Y C N$ [4]. Underlined aminoacids: selected epitope for polyclonal antibody production in rabbit. 
tumours including medulloblastoma, retinoblastoma, small cell lung cancer, glioblastoma and other embryonal tumours [17] suggesting the implication of MYCN dosage in cancer development and aggressive expressivity. In single copy MYCN (SCN) neuroblastoma cell lines, MYCN has also been demonstrated to enhance proliferation after bFGF administration [18]. Contrariwise, the protein exhibits pro-apoptotic properties in particular conditions such as drug-triggered apoptosis [19,20] or induction of the death receptor machinery by TRAIL [21].

Thus, MYCN protein exhibits dual properties in proliferation and apoptosis, both in physiological and in pathological conditions.

In the present work, we evidenced a link between MYCN transcription and the level of MYCN translation. In vitro translation of the two coding mRNAs led to different levels of MYCN expression, with $M Y C N^{\Delta 1 b}$ mRNA being the most efficient. Their translation was differently regulated by an uORF located in the long $5^{\prime}$ untranslated region of exon $1 \mathrm{a} / \mathrm{b}$. Moreover, we observed that the uORF of MYCN mRNA was able to up-regulate MYCN translation, whereas the uORF of $M Y C N^{\Delta 1 b}$ mRNA was not. Our results demonstrated a MYCN dosage effect in SH-EP cells in which high amounts of MYCN were anti-apoptotic after serum deprivation, compared to low levels or absence of MYCN. Finally, the UORF of MYCN ${ }^{\Delta 1 b}$ mRNA directed the translation of a new protein of unknown function, MYCNOT.

\section{Methods \\ Cell culture}

SH-EP cell line (an epithelial substrate-adherent Schwann-like clone issued from SK-N-SH neuroblastoma cell line[22] that do not express MYCN protein was cultured in RMPI 1640 (Sigma) supplemented with 10\% foetal calf serum (GIBCO), penicillin G (200 IU/mL; GIBCO), streptomycin sulphate $(200 \mu \mathrm{G} / \mathrm{mL}$; GIBCO) and L-glutamine ( $2 \mathrm{mM}$; GIBCO) at $37^{\circ} \mathrm{C}$ in an atmosphere containing $5 \% \mathrm{CO}_{2}$.

\section{Plasmids preparation}

Plasmid preparations were based on the Invitrogen Gateway ${ }^{\circledR}$ technology. Inserts were prepared from human foetal brain mRNAs (Clontech) with a forward primer specific to the very beginning of exon $1 \mathrm{a} / \mathrm{b}$ at +1865 (according to Genbank Y00664) flanked with an attB1 sequence. Depending on the desired construct, three reverse primers extended with an attB2 sequence were designed. The first one, for $p-u O R F / M Y C N$ was complimentary to the sequence of the penultimate nucleotides of the first stop codon of the MYCN mRNA in frame with the uAUG codon located at +1894 . The second one, for $p$ $u O R F / M Y C N^{\Delta 1 b}$, was complimentary to the sequence of the penultimate nucleotides of the first stop codon of
$M Y C N^{\Delta 1 b}$ mRNA in frame with the same uAUG codon. The third reverse primer, for $p-M Y C N$ and $p-M Y C N \Delta 1 b$, was complementary to the sequence of the penultimate nucleotides of the MYCN stop codon in exon 3. DNAs amplified from $M Y C N$ and $M Y C N^{\Delta 1 b}$ mRNAs were inserted into pDEST40 according to Invitrogen Gateway ${ }^{\circledR}$ protocols with a C-terminal V5 epitope tag for visualizing protein translation.

The plasmids $p-M Y C N^{m u t}$ and $p-M Y C N^{\Delta 1 b}$, mut were obtained respectively from $p-M Y C N$ and $p-M Y C N^{\Delta} 1 b$ by mutation of the upstream AUG located in +1894 into an AUC using the Quickchange ${ }^{\circledast}$ Site-Directed Mutagenesis kit (Stratagene).

\section{Cell transfection}

For translational studies, three independant experiments were conducted in duplicate: SH-EP cells were sowed at a density of 200000 cells in 6-wells plates and transfected the next day with $3.6 \mu \mathrm{g}$ of purified MYCN-derived plasmids or control $p c D N A / G W-40 /$ lacZ (Invitrogen), $0.4 \mu \mathrm{g}$ p-EGFP (Clontech) and $8 \mu \mathrm{L}$ Lipofectamine 2000 (Invitrogen). Cells were harvested 24 hours after transfection.

For apoptosis experiments, three independent experiments were conducted in quadruplate: SH-EP cells were sowed at a density of 200000 cells in 6-wells plates and cultured in RMPI 1640 supplemented with $0.5 \%$ foetal calf serum, penicillin G (200 IU/mL), streptomycin sulphate $(200 \mu \mathrm{G} / \mathrm{mL})$ and L-glutamine $(2 \mathrm{mM})$ for 48 hours at $37^{\circ} \mathrm{C}$ in an atmosphere containing $5 \% \mathrm{CO}_{2}$, then transfected with $3.6 \mu \mathrm{g}$ of $p-M Y C N$, p-MYCN ${ }^{\Delta 1 b}$ or $p c D N A / G W$ 40/lacZ, $0.4 \mu \mathrm{g}$ pEGFP and $8 \mu \mathrm{L}$ Lipofectamine 2000. After transfection, cells were cultured for an additional day in the same medium supplemented with $10 \%$ foetal calf serum.

\section{Western blotting}

Proteins $(40 \mu \mathrm{g})$ from cell lysates or from a human foetal and adult brain (protein Medley ${ }^{\mathrm{Tm}}$; BD Biosciences) were separated by SDS-PAGE and transferred to $0.2 \mu \mathrm{m}$-nitrocellulose membranes (Biorad). Protein levels were determined using:

- a mouse anti-V5 epitope monoclonal antibody (1:5000, Invitrogen),

- a mouse anti-human $\beta$-ACTIN monoclonal antibody (1:200000, Sigma),

- a rabbit anti-NGAERSPQSPAGRRA [anti-MYCNOT] peptide polyclonal antibody (1:100, Eurogentec), whose specificity was checked by manufacturer

- a mouse anti-human MYCN monoclonal antibody, clone B8.4.B (1:1000, BD Pharmingen). 
Primary antibodies were detected using goat anti-mouse (1:10000, Sigma) or anti-rabbit (1:3000, Sigma) horseradish peroxidase-conjugated secondary antibodies, and visualized using an enhanced chemiluminescence HRP substrate (Millipore).

\section{Cell viability assay}

Cell viability was measured with Uptiblue viable cell counting reagent (Uptima) before serum deprivation and one day after transfection: cells were incubated for two hours after addition of $10 \%$ Uptiblue, fluorescence was measured with $530 \mathrm{~nm}$ excitation wavelength and 590 $\mathrm{nm}$ emission wavelength.

A one-sided student-t test was performed on the serum deprivation-induced apoptosis calculated as the fluorescence difference between the two measures.

\section{Results}

\section{MYCN and MYCN ${ }^{\mathrm{lb}} \mathrm{mRNAs}$ are differently translated}

Since alternative splicing of exon $1 \mathrm{~b}$ affects a potential upstream open reading frame (uORF), we speculated that it could influence the translation of MYCN protein. Vectors $p-M Y C N$ and $p-M Y C N^{\Delta 1 b}$ were prepared to allow the translation of MYCN respectively from these two mRNAs. In SH-EP neuroblastoma cells, transfection assays followed by Western blot showed no MYCN expression in presence of the control plasmid ( $p c D N A / G W 40 /$ lacZ), weak but detectable translation from $p-M Y C N$, whereas a very high amount of protein was obtained with $p$ $M Y C N^{\Delta 1 b}$ (Fig. 2a). The observed differences are not a simple consequence of experimental variations in either transfection efficacy, because cotransfection of $p$-EGFP induced no difference in the number of GFP-expressing cells between experiments (data not shown), or RNA transcription or stability, because semi quantitative RT-PCR analysis showed no difference in the levels of MYCN and $M Y C N^{\Delta 1 b}$ transcripts brought by plasmids (data not shown). Upstream ORF is usually known for cis-acting inhibitory effect on translation of the major protein. To test this hypothesis, the upstream AUG was mutated to AUC to produce $p-M Y C N^{m u t}$ and $p-M Y C N^{\Delta 1 b, m u t}$ vectors. MYCN levels in SH-EP cells clearly diminished when it was translated from MYCN transcripts, but not from $M Y C N^{\Delta 1 b}$ transcripts (Fig. 2b).

\section{High MYCN dosage enhances cell viability}

To explore the effect of MYCN dosage, SH-EP cells were subjected to apoptosis by 48-hour serum deprivation, then transfected with either control pcDNA/GW40/lacZ, $p$ $M Y C N$, or $p-M Y C N^{\Delta 1 b}$ plasmids. As shown in Table 1, when SH-EP cells did not express ( $p c D N A / G W-40 / l a c Z$ transfected cells) or expressed low amount ( $p$-MYCN transfected cells) of MYCN protein, serum deprivation induced similar cell loss (respectively $35.56 \%+/-6.68 \%$ and $34.94+/-7.19 \%$; $\mathrm{p}=0.60)$. When SH-EP cells

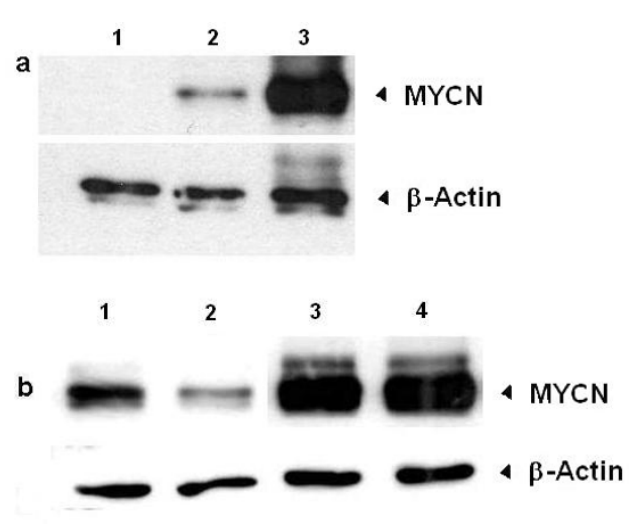

Figure 2

Exon Ib-splicing, uAUG and MYCN translation. a) Western blot analysis of $40 \mu \mathrm{g}$ SH-EP neuroblastoma cells transfected with either control pcDNA/GW40/lacZ (lane I), pMYCN (lane 2) or p-MYCN $\Delta l b$ (lane 3). Results obtained with upper panel: a monoclonal antibody against MYCN (I:1000) and -lower panel: a monoclonal antibody against $\beta$-Actin ( I: 10000). b) Western blot analysis of $40 \mu \mathrm{g}$ SH-EP cells transfected with either $p-M Y C N$ (lane I), $p-M Y C N$ mut (lane 2), $p-M Y C N \Delta I b$ (lane 3) or p-MYCN $\Delta \mathrm{lb}$, mut (lane 4). Results obtained with -upper panel: the anti-MYCN antibody $(1: 1000)$ and -lower panel: the anti $\beta$-Actin antibody $(\mathrm{I}: 10000)$.

expressed high levels ( $p$-MYCN ${ }^{\Delta 1 b}$ transfected cells) of MYCN protein, apoptosis $(26.72 \%+/-8.09 \%)$ was significantly ( $\mathrm{p}=0.01$ and $\mathrm{p}=0.02$ respectively compared to previous conditions) reduced by one third.

\section{MYCNOT is translated from a upstream AUG of MYCN Ib mRNA}

We speculated that uAUG, located in +1894 (according to GenBank: Y00664, may initiate the translation and we assessed the importance of alternative splicing of exon $1 \mathrm{~b}$.

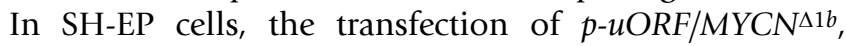

Table I: MYCN dose-dependant anti-apoptotic effect after serum deprivation.

Transfected plasmids

Cell viability (\%)

pcDNA/GW-40/lacZ

$64.44+/-6.68$

\begin{tabular}{cc}
\hline PMYCN & $65.06+/-7.19 \mathrm{a}$ \\
\hline pMYCN & $73.27+/-8.09 \mathrm{~b}, \mathrm{c}$
\end{tabular}

MYCN dose-dependant enhanced SH-EP viability after serum deprivation measured with Uptiblue viable cell counting reagent (Uptima). a $p=0.60$ compared with $p C D N A /$ $G W-40 / l a c Z ;{ }^{b} p=0.01$ compared with pCDNA/GW-40/lacZ; ${ }^{c} p=0.02$ compared with $P M Y C N$ 
which contains the uORF of MYCN ${ }^{\Delta 1 b}$ mRNA, allowed the production of a V5 epitope-tagged protein of approximately $15 \mathrm{kDa}$, whereas the transfection of $p-u O R F / M y c$, which contains the uORF of the full length MYCN transcript, did not (Fig. 3a). This $11.8 \mathrm{kDa}$ new protein was named MYCNOT: MYCN Overlap Transcript.

To validate the existence of endogenous MYCNOT, we performed a Western blot analysis using a specifically designed polyclonal antibody raised in rabbit against a $\mathrm{N}$ terminal epitope (NGAERSPQSPAGRRA) [anti-MYCNOT] of the hypothetical protein. The designed MYCNOT antibody was able to detect in transfected SH-EP cells with $p-u O R F / M Y C N^{\Delta 1 b}$ the same protein detected with the V5 epitope antibody (Fig. 3b), The anti-MYCNOT antibody was able to detect a $\sim 12 \mathrm{kDa}$ protein in foetal but not in adult brain (Fig. 3c), thus confirming the existence of an endogenous MYCNOT protein. An analysis of MYCNOT

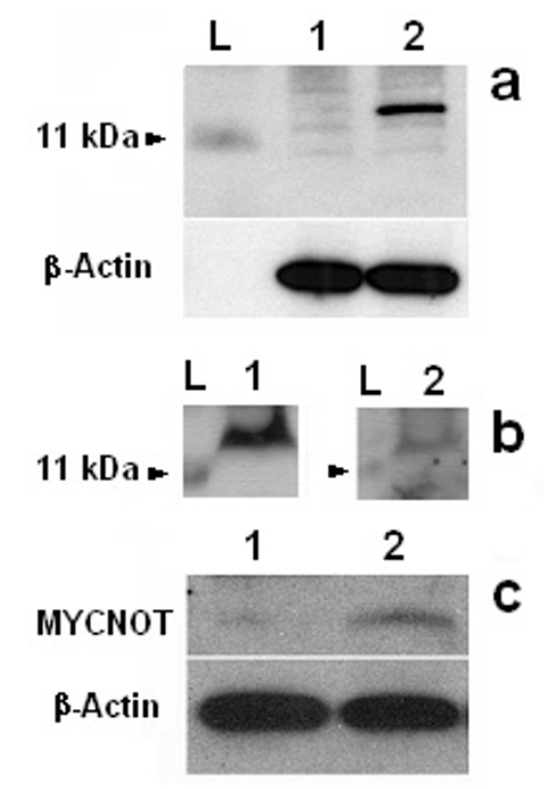

\section{Figure 3}

Translation of UORF and existence of MYCNOT. a) SH-EP cells were transfected with either $p-u O R F / M Y C N$ (lane I) or $p$-uORF/MYCN ${ }^{\Delta l b}$ (lane 2). Western blot was conducted on $40 \mu \mathrm{g}$ proteins, 48 hours after transfection with -upper panel: a monoclonal antibody against the V5 epitope ( $1: 300)$ and -lower panel: the anti $\beta$-Actin antibody (I:I0000). L: protein ladder; b) SH-EP cells were transfected with $p$-uORFI $M_{Y C N}{ }^{\mathrm{l} b}$. Western blot was conducted on $40 \mu \mathrm{g}$ protein, 48 hours after transfection with -left panel: a monoclonal antibody against the $V 5$ epitope ( $1: 300)$ and -right panel: a polyclonal rabbit anti-NGAERSPQSPAGRRA peptide [antiMYCNOT] polyclonal antibody (I:I00) L: protein ladder; c) Western blot analysis of $40 \mu \mathrm{g}$ protein extracts from adult (lane I) and foetal (lane 2) brain. Results obtained with upper panel: the anti-MYCNOT antibody $(1: 100)$ and -lower panel: the anti $\beta$-Actin antibody (I:I0000). sequence with BLAST and PROSITE software did not show any sequence or motif homology.

\section{Discussion}

Because upstream ORF are known to influence protein translation [23], we investigated the MYCN translation from the full length MYCN mRNA and the exon 1bspliced $M Y C N^{\Delta 1 b}$ mRNA. Only these two mRNAs are able to translate the MYCN protein. More recently, in 2005, van Bokhoven et al described a new exon 1a/2-spliced mRNA able to translate a new protein named $\triangle \mathrm{MYCN}[4]$. In SH-EP cells, we demonstrated that both MYCN and $M Y C N^{\Delta 1 b}$ were able to translate the MYCN protein, but MYCN translation from MYCN ${ }^{\Delta 1 b}$ mRNA was much more efficient. This difference may not be attributed to a differential stability of the two transcripts because they have the same half-life of approximatively 15 minutes [2]. But, that could be due to differences in the regulating activities of uORFs in the two mRNAs. Because, the coding AUG is several hundreds nucleotides after the stop codon of the uORF in MYCN mRNA compared to the overlapping uORF in MYCN ${ }^{\Delta 1 b}$ transcript, we should have expected a higher translation of MYCN protein from full length mRNA due to reinitiation $[6,23]$, but as already demonstrated, this mRNA contains an Internal Ribosome Entry Site (IRES) that could explain the higher initiation of translation at the major AUG in $M_{Y C N} \Delta 1 b$ mRNA $[5,24,25]$.

Upstream ORFs are usually known for their cis-acting inhibitory activity on the translation of the major protein [7,26-30]. To test this hypothesis, UAUG was mutated into AUC. This mutation had no effect on MYCN translation from $M Y C N^{\Delta 1 b}$ mRNA but significantly impacted the translation from MYCN mRNA. Thus, MYCN uORFs have different cis-regulatory activities in MYCN translation depending on the alternative splicing of exon $1 \mathrm{~b}$. In our conditions, the uORF of the MYCN ${ }^{\Delta 1 b}$ mRNA did not affect MYCN translation. Alternatively, the uORF transcribed from full length MYCN mRNA has cis-enhancing activity on MYCN translation. To our knowledge, only one team has shown that an UORF is able to augment the translation of the HIV-1 Env protein from the HIV-1 mRNA [30]. Taken together, our results suggest the existence of a new level of MYCN regulation. One hypothesis should be further explored: in cap-dependent conditions, low-level MYCN would be produced from the full length mRNA and this translation would be sustained by the activity of the uORF whereas in IRES-dependent conditions, high-level MYCN would be produced from exon 1b-spliced mRNA, independently of the uORF.

Numerous experiments have demonstrated important ontogenic [31] and oncogenic [14] roles. The amplification and overexpression of MYCN primarily found in $25 \%$ of neuroblastomas [16] and in other tumours 
including medulloblastoma, retinoblastoma, small cell lung cancer, glioblastoma and other embryonal tumours [17] suggest the implication of MYCN dosage in cancer development and aggressive expressivity.

Our results showed that, in transfected SH-EP neuroblastoma cells, high MYCN dosage obtained with $M Y C N^{\Delta 1 b}$ mRNA translation induces a weak but significant antiapoptotic effect after serum deprivation that was not observed with low MYCN expression obtained with MYCN mRNA. Our results do not fit the accepted proapoptotic properties of MYCN: using a MYCN-inducible SH-EP Tet21/N cell line, it has been demonstrated that MYCN overexpression enhances either doxorubicin- or platinum-induced apoptosis [19]. Using a similar approach, Cui et al have shown that the transfection of SH-EP cells with a $p B a b e-h y g r o / M Y C N$ vector sensitises the cells to TRAIL-triggered apoptosis[21]. But, as we did, Jasty et al have reported a significant increase of cell viability with high MYCN expression after 6 days of serum deprivation [32]. These different results and ours suggest that MYCN overexpression in SH-EP cells might have different effects depending on the existence of an intrinsic (serum deprivation) or extrinsic (TRAIL or drug-induced apoptosis) pathway-mediated apoptosis. Thus, MYCN dosage, depending on translation of the alternatively exon $1 \mathrm{~b}$ splicing mRNA, enhances cell viability after intrinsic pathway-mediated apoptosis.

As previously proposed, the UAUG codon located in exon 1a may initiate the translation of $\triangle \mathrm{MYCN}$, a new isoform of the MYCN protein [4]. It has also been hypothesized, but not proven at this time, that this uAUG is able to translate a protein (GenBank: AAG40001.1) [5]. We now demonstrated the existence of this $11.8 \mathrm{kDa}$ protein and named it MYCNOT: MYCN Overlap Transcript. Even if uORFs appear to apply to as much as $50 \%$ of the transcriptome $[6,7,23]$, only few papers have reported their translation in in-vitro experiments using chimeric tag-fusion proteins [23]. This is particularly true for the MYC gene, to which MYCN is related, which presents several uORFs: one $\mathrm{UORF}$ in exon 1 conducts to the translation of a protein of unknown function called MYCHEX1 [33]. To our knowledge, only one team, using two-dimensional chromatography and mass spectrometry analysis, has been able to prove the existence of eight proteins encoded by uORFs in human K562 and HEK293 cell lines [34]. Moreover, these small proteins $(<20 \mathrm{kDa})$ were not subject to rapid proteasome degradation suggesting functional activity [34]. The MYCNOT protein, which has no homology with MYCN, other known proteins or protein motifs, shares exon 1a-encoded amino acids with the putative $\triangle$ MYCN previously described [4]. Because MYCNOT is translated in foetal but not adult brain, we may hypothesize that it plays a role during neural development. Our results need further analysis to determine the functions of MYCNOT and might provide new insights into MYCN regulation.

\section{Conclusion}

The MYCN gene is transcribed into two major mRNAs which are differently translated. Higher levels of protein were seen with $M Y C N^{\Delta 1 b}$ mRNA. Existence of an upstream ORF was shown to have positive cis-regulatory activity on translation from MYCN but not from MYCN ${ }^{\Delta 1 b}$ mRNA. The high MYCN dosage obtained with $M_{Y C N}{ }^{\Delta 1 b}$ mRNA translation induces, in transfected SH-EP neuroblastoma cells, a weak but significant antiapoptotic effect after serum deprivation that was not observed with low MYCN expression.

Here, we show the translation of a new protein of unknown function from the upstream AUG of MYCN ${ }^{\Delta 1 b}$ mRNA.

In conclusion, further studies are now needed to explore the exact relationship between alternative splicing of exon $1 \mathrm{~b}, \mathrm{MYCN}$ dosage, and the mechanism, either extrinsic or intrinsic, underlying apoptosis.

\section{Competing interests}

The authors declare that they have no competing interests.

\section{Authors' contributions}

$\mathrm{RB}$ carried out the design of the study and manuscript writing and participated in plasmids preparation, cell culture and Western blotting experiments. SWV participated to design of the study and manuscript writing. CL participated to cell culture and Western blotting experiments. CDB participated to plasmids preparation, cell culture and Western blotting experiments. GT participated to cell culture and Western blotting experiments. ACJ participated to cell culture and Western blotting experiments. EG participated to cell culture and Western blotting experiments. AP participated to design of the study and manuscript writing. All authors read and approved the final manuscript."

\section{Acknowledgements}

The authors are grateful to Dr. A. Denuzière for statistical assistance and to Mrs M.-D. Reynaud for editorial assistance. This work was supported by INCa Projet Libre 2006-2008 PL 06-76.

\section{References}

I. Schwab M, Varmus HE, Bishop JM, Grzeschik KH, Naylor SL, Sakaguchi $A Y$, et al: Chromosome localization in normal human cells and neuroblastomas of a gene related to c-myc. Nature 1984, 308:288-29|.

2. Stanton LW, Bishop JM: Alternative processing of RNA transcribed from NMYC. Mol Cell Biol 1987, 7:4266-4272.

3. Ibson JM, Rabbitts PH: Sequence of a germ-line $\mathbf{N}$-myc gene and amplification as a mechanism of activation. Oncogene 1988, 2:399-402. 
4. van Bokhoven $\mathrm{H}$, Celli J, van Reeuwijk J, Rinne T, Glaudemans B, van Beusekom E, et al:: MYCN haploinsufficiency is associated with reduced brain size and intestinal atresias in Feingold syndrome. Nat Genet 2005, 37:465-467.

5. Jopling CL, Willis $A E: \mathbf{N}$-myc translation is initiated via an internal ribosome entry segment that displays enhanced activity in neuronal cells. Oncogene 200I, 20:2664-2670.

6. Kochetov AV, Ahmad S, Ivanisenko V, Volkova OA, Kolchanov NA, Sarai $A$ : uORFs, reinitiation and alternative translation start sites in human mRNAs. FEBS Lett 2008, 582:1293-1297.

7. Calvo SE, Pagliarini DJ, Mootha VK: Upstream open reading frames cause widespread reduction of protein expression and are polymorphic among humans. Proc Natl Acad Sci USA 2009, 106:7507-75 I2.

8. Landry JR, Mager DL, Wilhelm BT: Complex controls: the role of alternative promoters in mammalian genomes. Trends Genet 2003, 19:640-648.

9. Schwab M, Alitalo K, Klempnauer KH, Varmus HE, Bishop JM, Gilbert F, et al.: Amplified DNA with limited homology to myc cellular oncogene is shared by human neuroblastoma cell lines and a neuroblastoma tumour. Nature 1983, 305:245-248.

10. Sawai S, Shimono A, Wakamatsu Y, Palmes C, Hanaoka K, Kondoh H: Defects of embryonic organogenesis resulting from targeted disruption of the $\mathbf{N}$-myc gene in the mouse. Development 1993 , I I 7: 1445-1455.

II. Knoepfler PS, Cheng PF, Eisenman RN: $\mathbf{N}$-myc is essential during neurogenesis for the rapid expansion of progenitor cell populations and the inhibition of neuronal differentiation. Genes Dev 2002, 16:2699-27I2.

12. Okubo T, Knoepfler PS, Eisenman RN, Hogan BL: Nmyc plays an essential role during lung development as a dosage-sensitive regulator of progenitor cell proliferation and differentiation. Development 2005, 132: I363-1374.

13. Wakamatsu $\mathrm{Y}$, Watanabe $\mathrm{Y}, \mathrm{Nakamura} \mathrm{H}$, Kondoh $\mathrm{H}$ : Regulation of the neural crest cell fate by $\mathrm{N}$-myc: promotion of ventral migration and neuronal differentiation. Development 1997, 124:1953-1962.

14. Schwab M, Varmus HE, Bishop JM: Human N-myc gene contributes to neoplastic transformation of mammalian cells in culture. Nature 1985, 316:160-162.

15. Weiss WA, Aldape K, Mohapatra G, Feuerstein BG, Bishop JM: Targeted expression of MYCN causes neuroblastoma in transgenic mice. EMBO J 1997, 16:2985-2995.

16. Seeger RC, Brodeur GM, Sather H, Dalton A, Siegel SE, Wong KY, et al: Association of multiple copies of the N-myc oncogene with rapid progression of neuroblastomas. N Engl J Med I985, 313:1III-III6.

17. Pession A, Tonelli R: The MYCN oncogene as a specific and selective drug target for peripheral and central nervous system tumors. Curr Cancer Drug Targets 2005, 5:273-283.

18. Schweigerer L, Ledoux D, Fleischmann G, Barritault D: Enhanced MYCN oncogene expression in human neuroblastoma cells is associated with altered FGF receptor expression and cellular growth response to basic FGF. Biochem Biophys Res Commun I99I, I79: | 449-I 454.

19. Fulda S, Lutz W, Schwab M, Debatin KM: MycN sensitizes neuroblastoma cells for drug-triggered apoptosis. Med Pediatr Oncol 2000, 35:582-584.

20. Paffhausen T, Schwab M, Westermann F: Targeted MYCN expression affects cytotoxic potential of chemotherapeutic drugs in neuroblastoma cells. Cancer Lett 2007, 250:17-24.

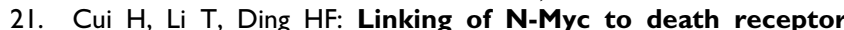
machinery in neuroblastoma cells. J Biol Chem 2005, 280:9474-948I.

22. Ross RA, Spengler BA, Biedler JL: Coordinate morphological and biochemical interconversion of human neuroblastoma cells. J Natl Cancer Inst 1983, 71:74|-747.

23. lacono M, Mignone F, Pesole G: uAUG and uORFs in human and rodent 5'untranslated mRNAs. Gene 2005, 349:97-105.

24. Cobbold LC, Spriggs KA, Haines SJ, Dobbyn HC, Hayes C, de Moor $\mathrm{CH}$, et al: Identification of internal ribosome entry segment (IRES)-trans-acting factors for the Myc family of IRESs. Mol Cell Biol 2008, 28:40-49.

25. Spriggs KA, Cobbold LC, Jopling CL, Cooper RE, Wilson LA, Stoneley $M$, et al.: Canonical initiation factor requirements of the Myc family of internal ribosome entry segments. Mol Cell Biol 2009 , 29:1565-1574.

26. Watatani $Y$, Ichikawa $K$, Nakanishi N, Fujimoto M, Takeda H, Kimura $\mathrm{N}$, et al:: Stress-induced translation of ATF5 mRNA is regulated by the 5'-untranslated region. J Biol Chem 2008, 283:2543-2553.

27. Pendleton LC, Goodwin BL, Solomonson LP, Eichler DC: Regulation of endothelial argininosuccinate synthase expression and NO production by an upstream open reading frame. Biol Chem 2005, 280:24252-24260.

28. Park EH, Lee JM, Pelletier J: The Tie2 $\mathbf{5}$ ' untranslated region is inhibitory to 5' end-mediated translation initiation. FEBS Lett 2006, 580: $\mid 309-1319$.

29. Martin MM, Buckenberger JA, Knoell DL, Strauch AR, Elton TS: TGFbeta(I) regulation of human AT(I) receptor mRNA splice variants harboring exon 2. Mol Cell Endocrinol 2006, 249:2I-3I.

30. Krummheuer J, Johnson AT, Hauber I, Kammler S, Anderson JL, Hauber J, et al.: A minimal uORF within the HIV-I vpu leader allows efficient translation initiation at the downstream env AUG. Virology 2007, 363:26I-27I.

31. Hurlin PJ: N-Myc functions in transcription and development. Birth Defects Res C Embryo Today 2005, 75:340-352.

32. Jasty R, van Golen C. Lin HJ, Solomon G, Heidelberger K, Polverini P, et al.: Bcl-2 and M-Myc coexpression increases IGF-IR and features of malignant growth in neuroblastoma cell lines. Neoplasia 200I, 3:304-3I3.

33. Nanbru C, Prats AC, Droogmans L, Defrance P, Huez G, Kruys V: Translation of the human c-myc PO tricistronic mRNA involves two independent internal ribosome entry sites. Oncogene 200I, 20:4270-4280.

34. Oyama M, Kozuka-Hata H, Suzuki Y, Semba K, Yamamoto T, Sugano $S$ : Diversity of translation start sites may define increased complexity of the human short ORFeome. Mol Cell Proteomics 2007, 6:1000-1006

\section{Pre-publication history}

The pre-publication history for this paper can be accessed here:

http://www.biomedcentral.com/1471-2407/9/445/pre pub

Publish with Biomed Central and every scientist can read your work free of charge

"BioMed Central will be the most significant development for disseminating the results of biomedical research in our lifetime. "

Sir Paul Nurse, Cancer Research UK

Your research papers will be:

- available free of charge to the entire biomedical community

- peer reviewed and published immediately upon acceptance

- cited in PubMed and archived on PubMed Central

- yours - you keep the copyright 